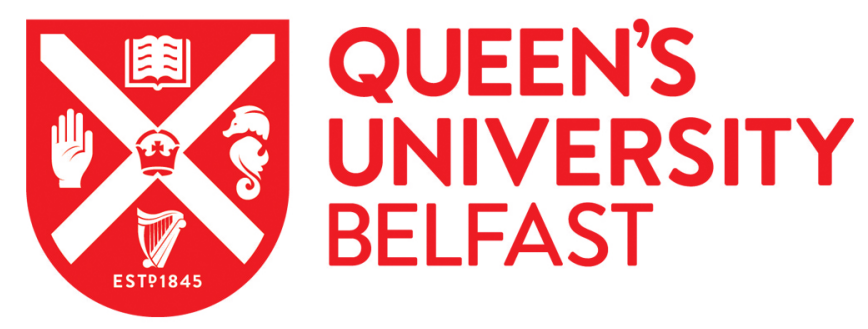

\title{
Photoelectrochemistry of Pristine Mono- and Few-Layer MoS2
}

Velicky, M., Bissett, M. A., Woods, C. R., Toth, P. S., Georgiou, T., Kinloch, I. A., Novoselov, K. S., \& Dryfe, R. A. W. (2016). Photoelectrochemistry of Pristine Mono- and Few-Layer MoS ${ }_{2}$. Nano Letters, 16(3), $2023-2032$. https://doi.org/10.1021/acs.nanolett.5b05317

\section{Published in:}

Nano Letters

Document Version:

Publisher's PDF, also known as Version of record

Queen's University Belfast - Research Portal:

Link to publication record in Queen's University Belfast Research Portal

\section{Publisher rights}

(C) 2016 American Chemical Society

This is an open access article published under a Creative Commons Attribution (CC-BY) License

(http://pubs.acs.org/page/policy/authorchoice_ccby_termsofuse.html), which permits unrestricted use, distribution and reproduction in any medium, provided the author and source are cited.

\section{General rights}

Copyright for the publications made accessible via the Queen's University Belfast Research Portal is retained by the author(s) and / or other copyright owners and it is a condition of accessing these publications that users recognise and abide by the legal requirements associated with these rights.

Take down policy

The Research Portal is Queen's institutional repository that provides access to Queen's research output. Every effort has been made to ensure that content in the Research Portal does not infringe any person's rights, or applicable UK laws. If you discover content in the Research Portal that you believe breaches copyright or violates any law, please contact openaccess@qub.ac.uk. 


\title{
Photoelectrochemistry of Pristine Mono- and Few-Layer $\mathrm{MoS}_{2}$
}

\author{
Matěj Velický, ${ }^{* \dagger}{ }^{\dagger}$ Mark A. Bissett, ${ }^{\dagger}$ Colin R. Woods, ${ }^{\ddagger}$ Peter S. Toth, ${ }^{\dagger}$ Thanasis Georgiou, ${ }^{\S}$ Ian A. Kinloch, ${ }^{\|}$ \\ Kostya S. Novoselov, ${ }^{\ddagger}$ and Robert A. W. Dryfe ${ }^{* \dagger}$ \\ ${ }^{\dagger}$ School of Chemistry and ${ }^{\ddagger}$ School of Physics and Astronomy, University of Manchester, Oxford Road, Manchester, M13 9PL, United \\ Kingdom \\ ${ }^{\S}$ Manchester Nanomaterials Ltd., 83 Ducie Street, Manchester, M1 2JQ, United Kingdom \\ "School of Materials, University of Manchester, Oxford Road, Manchester, M13 9PL, United Kingdom
}

Supporting Information
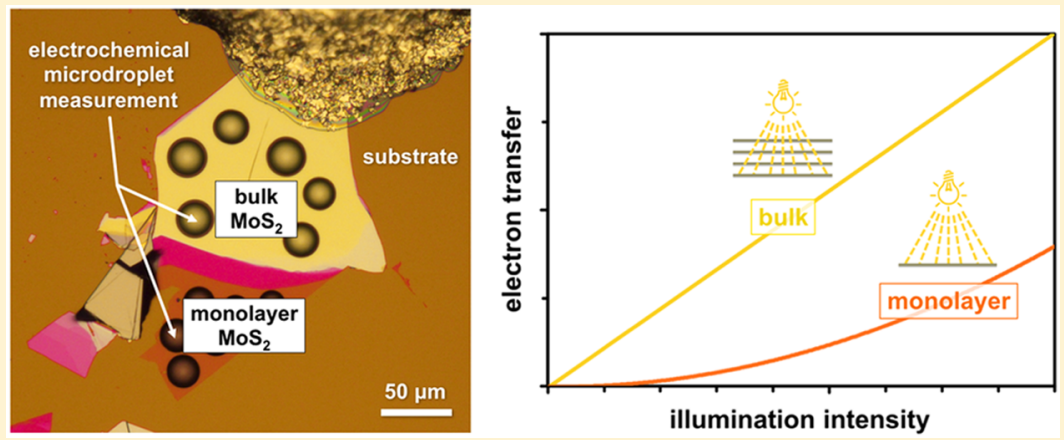

ABSTRACT: Two-dimensional crystals are promising building blocks for the new generation of energy materials due to their low volume, high surface area, and high transparency. Electrochemical behavior of these crystals determines their performance in applications such as energy storage/conversion, sensing, and catalysis. Nevertheless, the electrochemistry of an isolated monolayer of molybdenum disulfide, which is one of the most promising semiconducting crystals, has not been achieved to date. We report here on photoelectrochemical properties of pristine monolayer and few-layer basal plane $\mathrm{MoS}_{2}$, namely the electron transfer kinetics and electric double-layer capacitance, supported by an extensive physical and chemical characterization. This enables a comparative qualitative correlation among the electrochemical data, $\mathrm{MoS}_{2}$ structure, and external illumination, although the absolute magnitudes of the electron transfer and capacitance are specific to the redox mediator and electrolyte used in these measurements $\left(\left[\mathrm{Ru}\left(\mathrm{NH}_{3}\right)_{6}\right]^{3+/ 2+}\right.$ and $\mathrm{LiCl}$, respectively). Our work shows a strong dependence of the electrochemical properties on the number of $\mathrm{MoS}_{2}$ layers and illumination intensity and proves that an effective interlayer charge transport occurs in bulk $\mathrm{MoS}_{2}$. This highlights the exciting opportunities for tuning of the electrochemical performance of $\mathrm{MoS}_{2}$ through modification of its structure, external environment, and illumination.

KEYWORDS: Molybdenum disulfide, two-dimensional, electron transfer, capacitance, illumination

M olybdenum disulfide has been the flagship material in the research of two-dimensional (2D) materials beyond graphene. ${ }^{1}$ The main use of $\mathrm{MoS}_{2}$ as a solid lubricant ${ }^{2}$ has been extended to research in optoelectronics, photovoltaics, and sensors, ${ }^{3}$ following the recent boom in $2 \mathrm{D}$ materials. Devices fabricated from thin layers of pristine $\mathrm{MoS}_{2}$ have recently been shown to have excellent charge carrier mobility $\left(>30,000 \mathrm{~cm}^{2}\right.$ $\left.\mathrm{V}^{-1} \mathrm{~s}^{-1}\right),{ }^{4}$ and even exhibit superconducting behavior under sufficiently high doping. ${ }^{5} \mathrm{MoS}_{2}$ is a semiconducting member of a large family of layered transition metal dichalcogenides (TMDCs) ${ }^{6}$ with a indirect-direct band gap transition between bulk $(\sim 1.2 \mathrm{eV})$ and monolayer $(\sim 1.8 \mathrm{eV})$ form. ${ }^{7}$ Mono- and few-layer $\mathrm{MoS}_{2}$ preparation methods include the "scotch-tape" mechanical exfoliation ${ }^{8}$ and liquid-phase exfoliation of natural molybdenite crystals ${ }^{9}$ and also synthetic routes such as chemical vapor deposition (CVD), ${ }^{10}$ or hydrothermal growth. ${ }^{11}$
A large portion of $\mathrm{MoS}_{2}$ research focuses on applications in energy storage and conversion including batteries, ${ }^{12}$ solar cells, ${ }^{13}$ supercapacitors, ${ }^{14}$ and fuel cells. ${ }^{15}$ Electron transfer (ET) kinetics and electric double-layer capacitance (EDLC) are the two key electrochemical properties, which determine performance of $\mathrm{MoS}_{2}$ in these applications. While bulk $\mathrm{MoS}_{2}$ has been studied to some extent, ${ }^{16-19}$ there is a clear lack of electrochemical knowledge on mono- or few-layer $\mathrm{MoS}_{2}$. Recently, electrochemistry of thin layers of liquid-phase exfoliated $\mathrm{MoS}_{2}$ has been reported and shown to be significantly affected by the method of preparation. ${ }^{20,21}$ Liquid-exfoliated materials, however, behave differently than pristine $\mathrm{MoS}_{2}$, and, exhibit inferior electrochemical perform-

Received: December 31, 2015

Revised: January 28, 2016

Published: February 3, 2016 

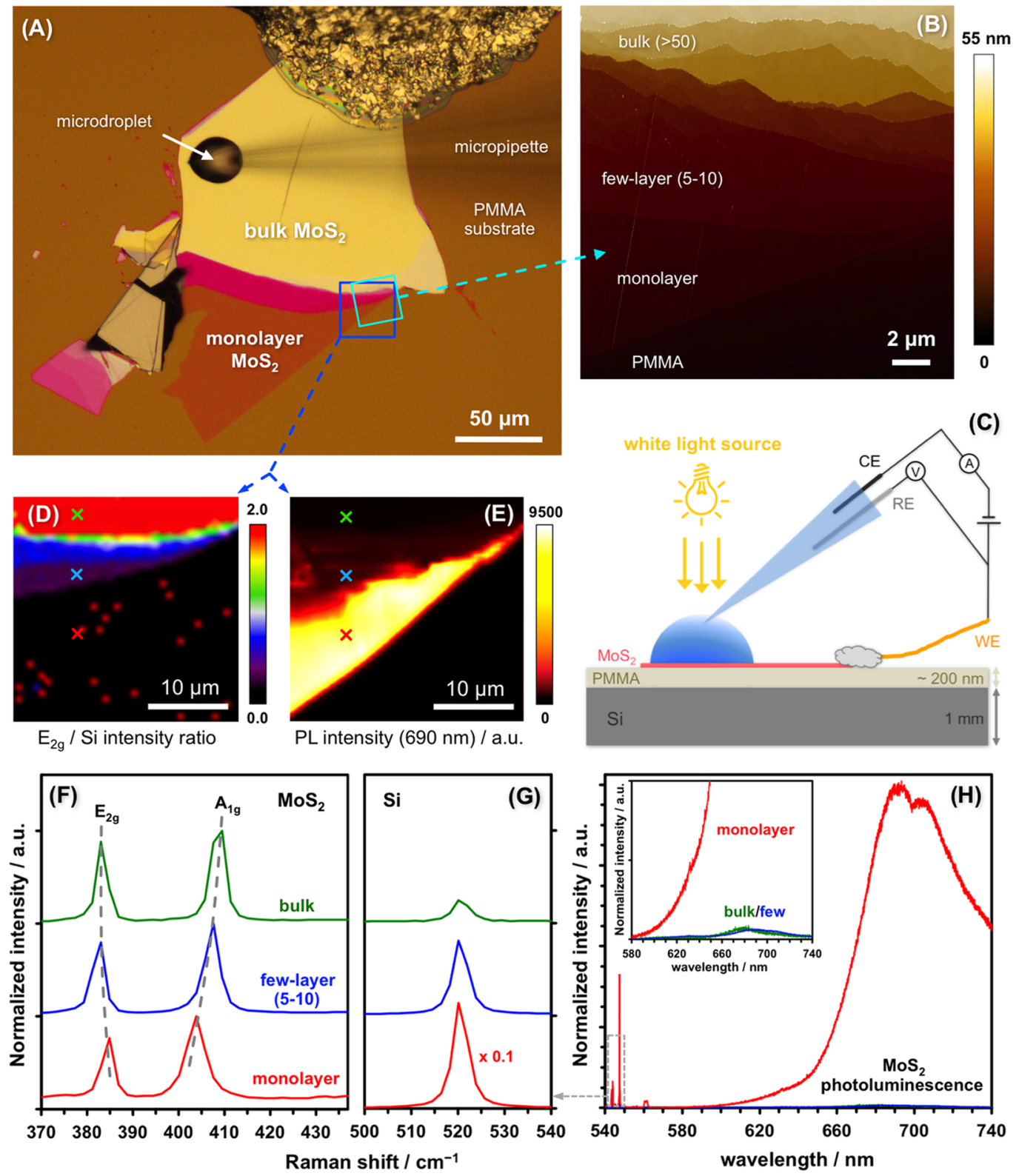

Figure 1. Optical microscopy, AFM, photoelectrochemical setup, Raman spectroscopy, and PL measurement of MoS 2 layers. (A) Optical micrograph of an $\mathrm{MoS}_{2}$ flake on PMMA-coated Si substrate. (B) AFM micrograph of a selected monolayer/few-layer/bulk flake region. (C) Schematic of the photoelectrochemical setup. (D) Raman map of the $\mathrm{E}_{2 \mathrm{~g}} / \mathrm{Si}$ intensity ratio. (E) PL intensity map at $690 \mathrm{~nm}$ wavelength. (F) and (G) Raman spectra showing the two main $\mathrm{MoS}_{2}$ bands and the $\mathrm{Si}$ band, respectively, and their evolution with the number of MoS layers. (H) PL spectra of the monolayer/few-layer/bulk $\mathrm{MoS}_{2}$. The areas used for the AFM measurement (B) and the Raman (D) and PL (E) maps are indicated in (A) by light blue and dark blue squares, respectively. The Raman and PL spectra of $(\mathrm{F}-\mathrm{H})$ were recorded at spots indicated by colored crosses in (D,E), respectively.

ance due to the small lateral size of the flakes, solvent residues, and impurity adsorbates. CVD-grown $\mathrm{MoS}_{2}$ has recently been shown to have thickness-dependent activity toward hydrogen evolution reaction. ${ }^{22}$ Importantly, electrochemical response of a pristine, isolated monolayer $\mathrm{MoS}_{2}$ crystal has not been reported to date. This lack of fundamental work is most likely linked to difficulties in preparation, which has been the main reason for limited research on mechanically exfoliated graphene. ${ }^{23-27}$

In this work, we isolate and characterize high-quality, pristine $\mathrm{MoS}_{2}$ monolayers and multilayers, and measure the ET kinetics and EDLC of their basal planes in aqueous electrolyte solutions. The magnitude of these key electrochemical properties increases with the surface density of electronic states (DOS), reflects surface oxidation or contamination, and is also an indirect measurement of the $\mathrm{MoS}_{2}$ conductivity. ET kinetics especially can vary over a several orders of magnitude due to these factors with its absolute value depending on the self-exchange rate of the selected redox mediator. In this study, we use a $\left[\mathrm{Ru}\left(\mathrm{NH}_{3}\right)_{6}\right]^{3+/ 2+}$ outer-sphere redox mediator, which is believed to be a nonadsorbing molecule insensitive to surface groups, meaning that the relative changes in its ET kinetics reflect the differences in the DOS of $\mathrm{MoS}_{2}{ }^{28}$ Atomically thin $\mathrm{MoS}_{2}$ layers are prepared using mechanical exfoliation of natural molybdenite crystals on a polymer-coated silicon substrate, yielding flakes of relatively large lateral dimensions, up to several hundred micrometers. A range of techniques 
including optical microscopy, Raman spectroscopy, photoluminescence (PL) measurement, atomic force microscopy (AFM), and X-ray photoelectron spectroscopy (XPS) were employed to determine the thickness of the $\mathrm{MoS}_{2}$ flakes, surface quality, and chemical composition. Localized photoelectrochemical measurement on individual single-crystals was carried out under white light illumination of a controlled intensity. Both electron transfer and capacitance are shown to depend on the number of $\mathrm{MoS}_{2}$ layers, which is a direct consequence of the thickness-dependent light absorption and subsequent photogeneration of free charge carriers.

Results and Discussion. Physical and Chemical Characterization of $\mathrm{MoS}_{2}$. Figure 1 summarizes the main characterization techniques. High optical contrast on a Si wafer coated with a thin layer of poly(methyl methacrylate) (PMMA) allows $\mathrm{MoS}_{2}$ flakes of all thicknesses to be located and visualized using optical microscopy (Figure 1A). The thickness of few-layer (510) and bulk $\mathrm{MoS}_{2}$ flakes can reliably be determined using AFM (Figure 1B) but the thinnest flakes (1-3) suffer from adventitious adsorbates and flake-substrate equilibrium separation, ${ }^{29,30}$ which increase their AFM-derived thickness by $0.5-$ $1.0 \mathrm{~nm}$ (Supporting Figure S1). Foreign adatoms on thin $\mathrm{MoS}_{2}$ crystals causing such discrepancies were first observed by Frindt, ${ }^{31}$ and more recently, hydrocarbon adsorbates, directly affecting the electrochemical performance of $\mathrm{MoS}_{2}$ have been confirmed. ${ }^{19}$ An aqueous microdroplet of electrolyte solution was placed on the $\mathrm{MoS}_{2}$ basal plane surface using an electrically controlled micropipette, allowing a localized measurement of electron transfer and capacitance at the $\mathrm{MoS}_{2}$ /liquid interface in a standard three-electrode configuration (Figure 1A,C). White light illumination was used to generate free charge carriers in the semiconducting $\mathrm{MoS}_{2}$ (irradiance calibration curves are shown in Supporting Figure S2). Optical microscopy and AFM were complemented with Raman spectroscopy and PL measurement, which, as shown in Figure 1D-H, reliably distinguish between mono-, bi-, trilayer and thicker flakes. The two most intense Raman phonon modes, corresponding to the in-plane $\left(E_{2 g}\right)$ and out-of-plane $\left(A_{1 g}\right)$ lattice vibrations, exhibit hardening and softening, respectively, when transitioning from bulk to monolayer $\mathrm{MoS}_{2}$ (Figure $1 \mathrm{~F}$ ). ${ }^{32}$ The $\mathrm{A}_{1 \mathrm{~g}}-\mathrm{E}_{2 \mathrm{~g}}$ Raman shift difference was used for an accurate determination of the number of layers using an appropriate calibration (Supporting Figure S3). The $520 \mathrm{~cm}^{-1}$ Raman mode of the underlying Si, which is $\sim 10$ times more intense for monolayer than few-layers (5-20) and further diminishes for bulk $\mathrm{MoS}_{2}$ (>50 layers), was also used to assess the flake thickness (Figure $1 \mathrm{G}$ ). Furthermore, the PL of a monolayer is about $100 \times$ more intense than that of the bulk crystal, as demonstrated in Figure $1 \mathrm{H}$. Figure $1 \mathrm{D}, \mathrm{E}$ shows the Raman $\mathrm{E}_{2 \mathrm{~g}} / \mathrm{Si}$ intensity ratio and $\mathrm{PL}$ maps of the selected regions in Figure 1A. The dependencies of the Si Raman and $\mathrm{MoS}_{2}$ PL intensity on the flake thickness are shown in Supporting Figure S4. Characterization of the flake surface using XPS (high-resolution spectra and imaging) confirmed that $\mathrm{MoS}_{2}$ is of semiconducting $2 \mathrm{H}$ phase with Mo and $S$ being the major element components (Supporting Figures S5 and S6). Only minor differences between the XPS spectra of monolayer and bulk $\mathrm{MoS}_{2}$ flakes were found. This comprehensive surface and photoelectrochemical characterization allows unambiguous assessment of the electrochemical performance of $\mathrm{MoS}_{2}$ and unraveling of its dependence on $\mathrm{MoS}_{2}$ thickness and external illumination.

Dependence of Electron Transfer on the Number of $\mathrm{MoS}_{2}$ Layers and Illumination. The ET kinetics of $\left[\mathrm{Ru}\left(\mathrm{NH}_{3}\right)_{6}\right]^{3+/ 2+}$ reduction/oxidation in aqueous solution at an $\mathrm{MoS}_{2}$ surface, expressed as the standard heterogeneous ET rate constant $\left(k^{0}\right)$ was determined from the peak-to-peak separation between the resultant reduction and oxidation waves (Figure $2 \mathrm{~A}$ ). $[\mathrm{Ru}-$
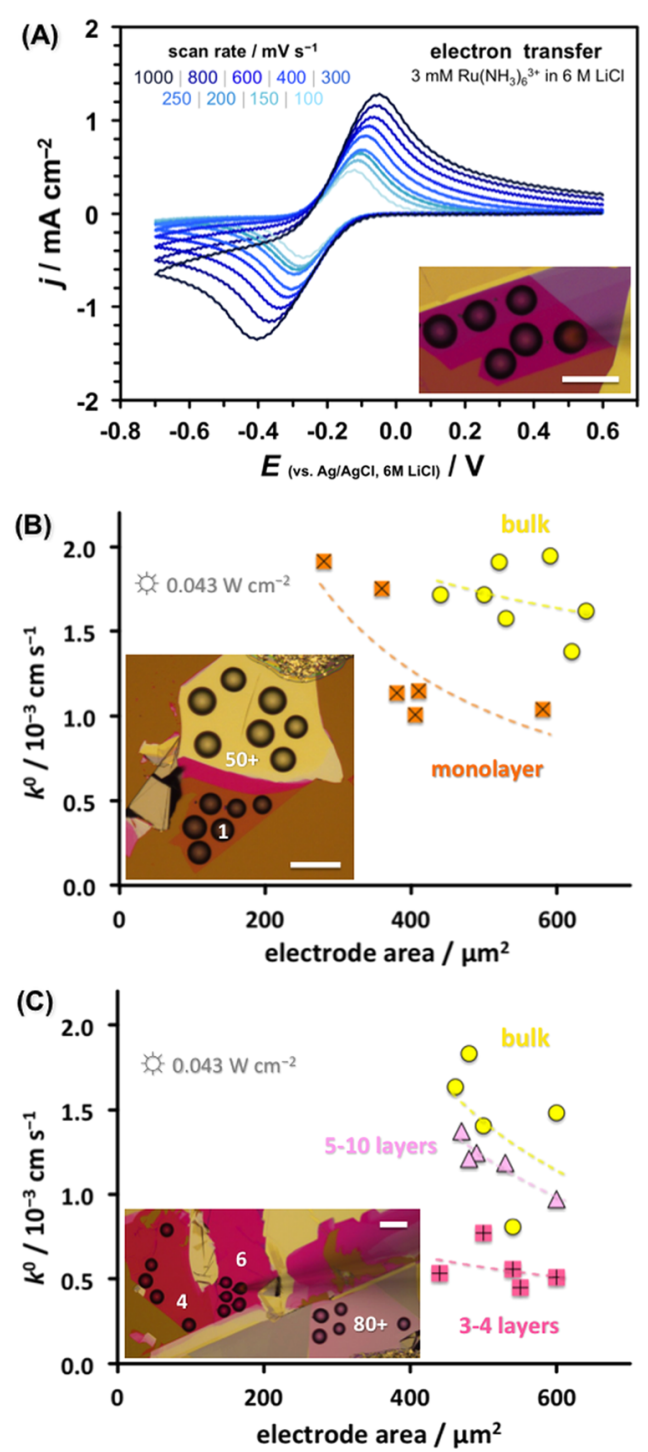

Figure 2. Electron transfer kinetics measurement. (A) Cyclic voltammograms of $\left[\mathrm{Ru}\left(\mathrm{NH}_{3}\right)_{6}\right]^{3+/ 2+}$ reduction/oxidation for the ET kinetics determination. $(\mathrm{B}, \mathrm{C})$ Heterogeneous ET rate constants $\left(k^{0}\right)$ for samples B and C, respectively. The ET kinetics (and also EDLC) are shown to be inversely proportional to the working electrode area due to light absorption effects (Supporting Figures S8 and S9). Plotting $k^{0}$ against the electrode area thus aids a direct comparison between layers of different thicknesses. The insets show optical micrographs of the individual droplet measurements, all scale bars denote $50 \mu \mathrm{m}$. The ET kinetics measured on some few-layer samples also depend on the distance from an electrical contact to a flake due to low conductivity of thin $\mathrm{MoS}_{2}$ (Supporting Figure S10).

$\left.\left(\mathrm{NH}_{3}\right)_{6}\right]^{3+/ 2+}$ is an outer-sphere redox mediator, which is thought to be insensitive to any surface functional groups and only to reflect the changes in the DOS of the electrode material. The $k^{0}$ was calculated from eq 1 for peak-to-peak separation, $\Delta E_{\mathrm{p}},>220 \mathrm{mV}$, or eq 2 for $\Delta E_{\mathrm{p}}<220 \mathrm{mV}$. An explicit expression for $k^{0}$ is ${ }^{33}$ 


$$
k^{0}=2.18\left(\frac{\alpha z F D v}{R T}\right)^{1 / 2} e^{\left(\alpha^{2} F / R T\right) z \Delta E_{\mathrm{p}}}
$$

where $\alpha$ is the transfer coefficient (here assumed to be 0.5 due to the reaction symmetry), $z=1$ is the number of electrons exchanged in the reaction, $F$ is the Faraday constant, $D$ is the diffusion coefficient of the redox mediator, $\nu$ is the scan rate, $R$ is the universal gas constant, and $T$ is the thermodynamic temperature. The Nicholson method, based on a normalized kinetic parameter, $\psi$, and its scan rate dependence, was also used $^{34}$

$$
\psi=k^{0} \sqrt{\frac{R T}{\pi n F D}} v^{-0.5}
$$

In this case, $\psi-\Delta E_{\mathrm{p}}$ working function was used to determine $\psi$ and then directly calculate $k^{035}$

$$
\psi=\frac{\left(-0.6288+0.0021 z \Delta E_{\mathrm{p}}\right)}{\left(1-0.017 z \Delta E_{\mathrm{p}}\right)}
$$

Voltammetry at scan rates between 0.1 and $1 \mathrm{~V} \mathrm{~s}^{-1}$ was performed for each droplet (Figure $2 \mathrm{~A}$ ) and mean $k^{0}$ value determined using the analytical methods above. It is important to note that the absolute value of ET kinetics measured here is specific to the selected $\left[\mathrm{Ru}\left(\mathrm{NH}_{3}\right)_{6}\right]^{3+/ 2+}$ redox mediator used in these measurements.

Natural 2D crystals often contain atomic vacancies, trace impurities, and adsorbates, which can all act as effective dopants. $^{36,37}$ The related sample-to-sample variation of $\mathrm{MoS}_{2}$ electrical properties is a common problem, which has been linked to various causes including defects, adsorbed water, and $\mathrm{MoS}_{2} /$ metal contact resistance, ${ }^{38-41}$ and confirmed here by the heterogeneity of the Raman and PL spectra across a monolayer $\mathrm{MoS}_{2}$ (Supporting Figure S7). Electrochemical response of the semiconducting $\mathrm{MoS}_{2}$, especially, is sensitive to illumination, as shown previously for bulk $\operatorname{MoS}_{2} \cdot{ }^{16,17,19}$ We have therefore specifically chosen to compare the responses of the directly adjacent parts (i.e., monolayer, few-layer, and bulk flakes) of a single-crystal $\mathrm{MoS}_{2}$ domain.

The single-crystal nature of these connected flakes, along with the constant illumination intensity, allow correlation between the electrochemical performance and number of $\mathrm{MoS}_{2}$ layers to be unraveled in a reliable fashion. Such an approach guarantees sample homogeneity and a reliable analysis. Figure $2 \mathrm{~B}-\mathrm{C}$ show the ET kinetics $\left(k^{0}\right)$ determined for monolayer, few-layer and bulk flakes of two different $\mathrm{MoS}_{2}$ samples (B and C). All 91 individual measurements performed across 8 different $\mathrm{MoS}_{2}$ samples $(\mathrm{A}-\mathrm{H})$ are shown in Supporting Figure S11. The ET kinetics vary significantly between each sample with maximum and minimum $k^{0}$ values being $1.95 \times$ $10^{-3} \mathrm{~cm} \mathrm{~s}^{-1}$ for bulk $\mathrm{MoS}_{2}$ (sample B) and $\sim 10^{-8} \mathrm{~cm} \mathrm{~s}^{-1}$ for monolayer $\mathrm{MoS}_{2}$ (sample G).

Importantly, the ET kinetics are found to increase systematically with increasing flake thickness, despite the sample-tosample variation described above. This is evident from measurements under differing illumination intensity, which reveal dependence of the ET kinetics on the irradiance for both monolayer and bulk $\mathrm{MoS}_{2}$, as shown in Figure 3A. Two main conclusions can be drawn from this graph: (1) bulk $\mathrm{MoS}_{2}$ exhibits faster ET kinetics than the monolayer $\mathrm{MoS}_{2}$; (2) while the ET kinetics of bulk $\mathrm{MoS}_{2}$ is linearly dependent on the irradiance, monolayer $\mathrm{MoS}_{2}$ shows stronger, nonlinear dependence on irradiance. The differences between the kinetics on
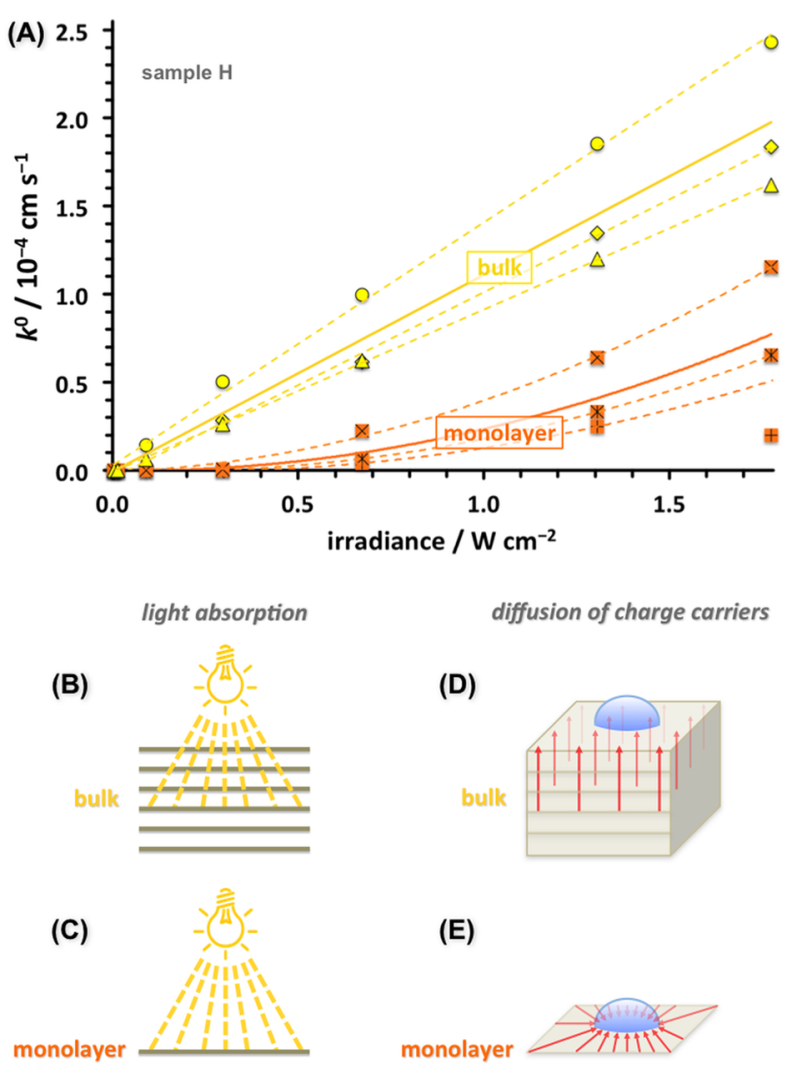

Figure 3. Electron transfer kinetics on monolayer and bulk $\mathrm{MoS}_{2}$. (A) Dependence of the monolayer and bulk $\mathrm{MoS}_{2}$ ET kinetics $\left(k^{0}\right)$ on irradiance, determined from individual droplet measurements (sample $\mathrm{H}$ ). Orange and yellow correspond to monolayer and bulk $\mathrm{MoS}_{2}$, respectively, the dashed lines/curves are the best fits for the individual droplet measurements, and the solid lines represent the averaged response. (B,C) Schematic diagrams demonstrating the efficiency of incident light absorption in bulk and monolayer $\mathrm{MoS}_{2}$, respectively. $(\mathrm{D}, \mathrm{E})$ Schematic diagrams showing the different charge carrier diffusion profiles in bulk and monolayer $\mathrm{MoS}_{2}$, respectively.

bulk and monolayer flakes can be explained by the total light absorption, which strongly depends on the number of $\mathrm{MoS}_{2}$ layers. While a single $\mathrm{S}-\mathrm{Mo}-\mathrm{S}$ layer only absorbs a small fraction of the incident light and therefore generates only a limited amount of free charge carriers contributing to the ET kinetics, many more $\mathrm{S}-\mathrm{Mo}-\mathrm{S}$ layers can convert the incident photons to a significant amount of charge carriers in bulk $\mathrm{MoS}_{2}$, as schematically shown in Figure 3B,C. On the other hand, the nonlinear kinetics-irradiance dependence in monolayer $\mathrm{MoS}_{2}$ is an unexpected observation. We explain this phenomenon by the fundamental difference in the diffusion of charge carriers within the bulk and monolayer $\mathrm{MoS}_{2}$, as shown in Figure 3D,E. The majority of the incident light $(>99 \%)$ is absorbed in the top 50 layers $(\sim 30 \mathrm{~nm})$, as determined from eq 6 considering the optical absorption of monolayer $\mathrm{MoS}_{2}$ to be $\sim 10 \%$ (the exact value depending on the reflectivity of an underlying substrate). ${ }^{42-44}$ As the light penetrates well inside the bulk $\mathrm{MoS}_{2}$ and generates charge carriers, which are electrochemically consumed at the top $\mathrm{MoS}_{2}$ layer, a linear diffusion profile is established between the deepest light-absorbing layer and $\mathrm{MoS}_{2}$ surface (Figure 3D). This results in a linear dependence of $k^{0}$ on the total radiant flux; the growing irradiance linearly increases the light penetration depth and concentration of the charge carriers within the top $\mathrm{MoS}_{2}$ layer. This also confirms 

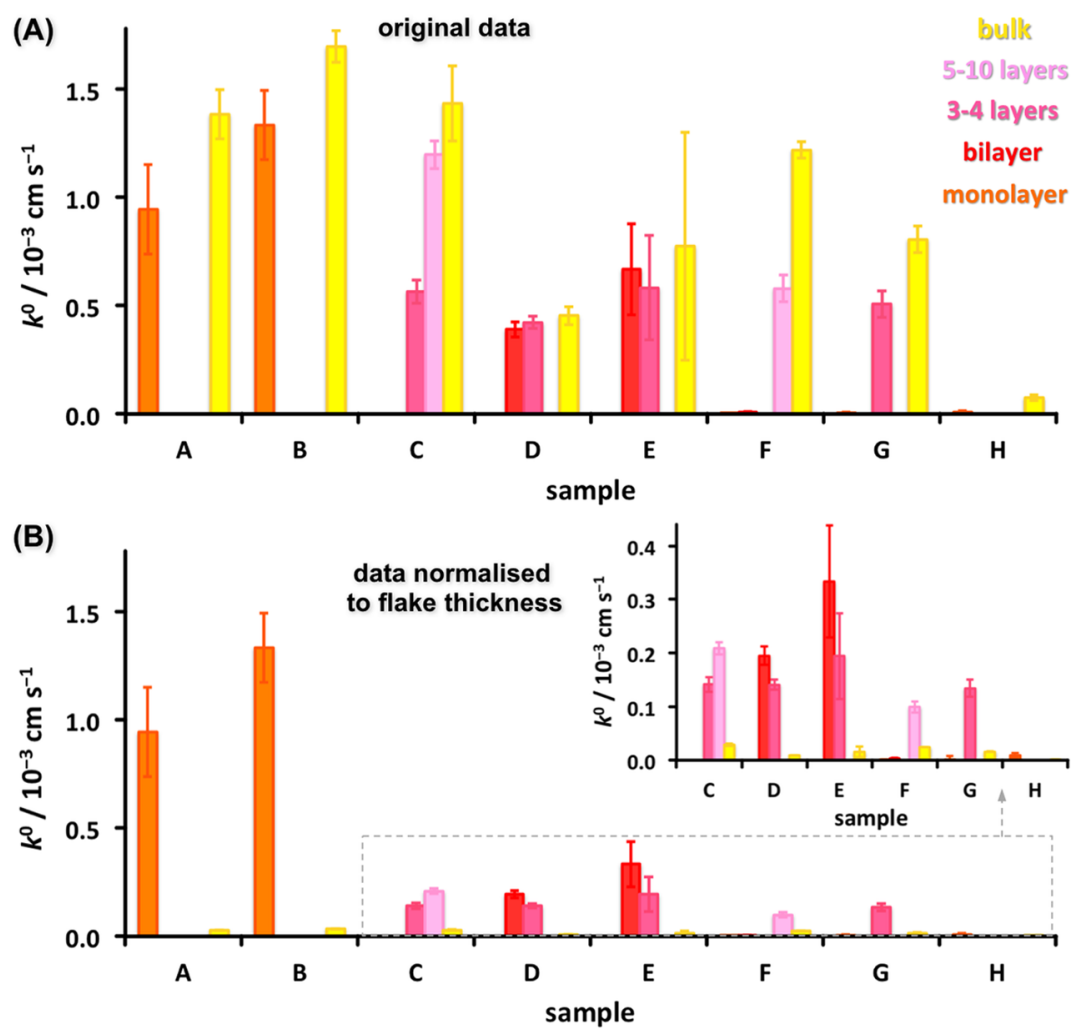

Figure 4. Correlation between the electron transfer kinetics and $\mathrm{MoS}_{2}$ thickness. (A) ET rate constant $\left(k^{0}\right)$ determined for $\mathrm{MoS}_{2}$ samples with varied flake thickness. (B) Same correlation but with the $k^{0}$ normalized to the number of $\mathrm{MoS}_{2}$ layers. To normalize all of the bulk data, $n=50$ layers was used in accordance with the discussed $>99 \%$ light absorption in bulk $\mathrm{MoS}_{2}$.

that an effective interlayer transport of charge carriers occurs between the individual sheets of $\mathrm{MoS}_{2}$, which is in contrast to recent observations. ${ }^{45}$ On the other hand, in monolayer $\mathrm{MoS}_{2}$ the diffusion of the charge carriers is only limited to a single light-absorbing sheet. This results in a radial charge carrier diffusion profile (Figure $3 \mathrm{E}$ ) and consequent nonlinear (parabolic) dependence of $k^{0}$ on irradiance. It was beyond the scope of this study to develop a fully quantitative model describing the dependence of $k^{0}$ (or other electrochemical function) on the number of layers. However, it is our hope that this will be the focus of future studies on the photoelectrochemistry of layered semiconducting materials.

Figure 4 summarizes all $k^{0}$ values measured for the samples $\mathrm{A}-\mathrm{H}$ as a function of the $\mathrm{MoS}_{2}$ thickness. For the sake of simplicity, the flake thickness was categorized into the following five different groups: monolayer, bilayer, 3-4 layers, 5-10 layers, and bulk (50+ layers). Although we were not able to establish a quantitative relationship between the interlayer charge carrier transport $\left(\mathrm{CT}_{\text {interlayer }}\right)$ and electron transfer between the top-layer $\mathrm{MoS}_{2}$ and $\left[\mathrm{Ru}\left(\mathrm{NH}_{3}\right)_{6}\right]^{3+/ 2+}\left(\mathrm{CT}_{\text {surface }}\right)$, it seems plausible to infer that $\mathrm{CT}_{\text {surface }}$ is faster for $\mathrm{MoS}_{2}$ flakes of high intrinsic conductivity than for the low conductivity ones (samples $\mathrm{A}$ and $\mathrm{H}$ in Figure 4 are examples of the former and latter case, respectively). The fact that the absolute ET kinetics of bulk $\mathrm{MoS}_{2}$ is always faster than that of mono- and few-layer $\mathrm{MoS}_{2}$ suggests that $\mathrm{CT}_{\text {surface }}$ (and not $\mathrm{CT}_{\text {interlayer }}$ ) is the limiting factor for the photoelectrochemical reaction. Figure 4A,B shows a comparison between the original kinetics data and the kinetics normalized to the number of $\mathrm{MoS}_{2}$ layers, respectively. This provides a useful assessment of the performance of $\mathrm{MoS}_{2}$ in relation to the quantity of the electrode material, that is, volume, mass, or active area.
Although the ET kinetics is an intensive physicochemical property, the normalization per thickness highlights that electrochemistry is limited to the top $\mathrm{MoS}_{2}$ layer, while the bulk only contributes to the interlayer transport of photogenerated charge carriers and does not actively participate in the electrochemical process. This is a solid justification for exfoliation of bulk $\mathrm{MoS}_{2}$ to thin flakes for energy storage/ conversion applications and it points toward a few-layer (5-10) $\mathrm{MoS}_{2}$ as a good compromise between a high surface area and a sufficiently fast ET.

It is also useful to analyze the absolute kinetics of the $\left[\mathrm{Ru}\left(\mathrm{NH}_{3}\right)_{6}\right]^{3+/ 2+}$ redox reaction at different semimetallic and metallic surfaces. The $\left[\mathrm{Ru}\left(\mathrm{NH}_{3}\right)_{6}\right]^{3+/ 2+}$ ET kinetics, determined via the same experimental method used here, increase as follows $\left(k^{0} / 10^{-3} \mathrm{~cm} \mathrm{~s}^{-1}\right):^{24}$ natural graphite, 0.053; highly ordered pyrolytic graphite, 0.35 , best performing $\mathrm{MoS}_{2}$ (bulk, under illumination), 1.7 (this work); Pt, 3.4; and $\mathrm{Au}, 3.7$. Note that these are values for surfaces aged in air for more than $24 \mathrm{~h}$, and that in the case of freshly cleaved graphite and $\mathrm{MoS}_{2}$ the $\left[\mathrm{Ru}\left(\mathrm{NH}_{3}\right)_{6}\right]^{3+/ 2}$ ET kinetics are comparable to those of unpolished $\mathrm{Pt}$ and Au. ${ }^{19,24}$ The above analysis shows that the magnitude of light-activated ET on natural $\mathrm{MoS}_{2}$ can be comparable with metallic electrodes.

Relationships among Capacitance, Electron Transfer, $\mathrm{MoS}_{2}$ Thickness, and PL. The capacitance was determined from the voltammetric background current measurement in a 6 $\mathrm{M} \mathrm{LiCl}$ supporting electrolyte aqueous solution within a potential window of $0.5 \mathrm{~V}$ where no faradaic processes occurred (Figure 5A). The electric double-layer capacitance was calculated from the following equation, adapted from ref 46 

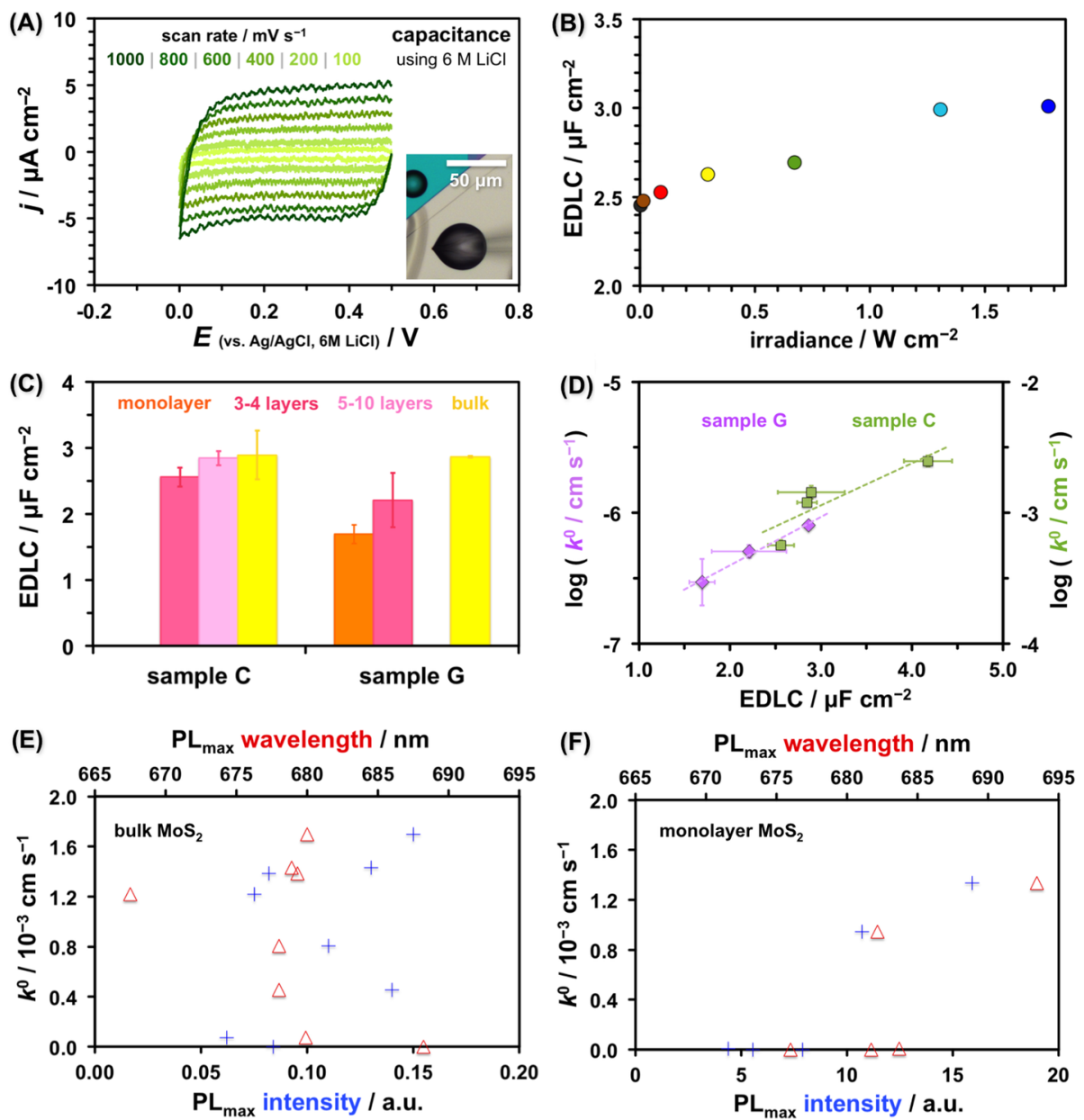

Figure 5. Relationships among capacitance, electron transfer, $\mathrm{MoS}_{2}$ thickness, and PL. (A) Cyclic voltammograms using $6 \mathrm{M} \mathrm{LiCl}$ supporting electrolyte for EDLC determination. (B) Dependence of EDLC on irradiance. (C) Dependence of EDLC on flake thickness determined for two different $\mathrm{MoS}_{2}$ samples. (D) ET kinetics correlation with EDLC for the same samples. (D,E) ET kinetics versus maximum PL wavelength and maximum PL intensity for bulk and monolayer $\mathrm{MoS}_{2}$, respectively.

$$
\operatorname{EDLC}=\frac{1}{2 \nu\left(E_{\max }-E_{\min }\right)} \oint_{E} I(E) \mathrm{d} E
$$

where $E$ is the applied potential and $E_{\max }\left(E_{\min }\right)$ are the maximum (minimum) potentials applied during the voltammetric scan. The mean EDLC was determined from several measurements at different scan rates, typically within the range of $0.1-3 \mathrm{~V} \mathrm{~s}^{-1}$. The EDLC was shown to depend only slightly on the scan rate (Supporting Figure S12).

The EDLC varied between 1.5-5.8 $\mu \mathrm{F} \mathrm{cm} \mathrm{cm}^{-2}$ and increased with increasing illumination intensity by $\sim 20 \%$ (from dark to $1.8 \mathrm{~W} \mathrm{~cm}^{-2}$ irradiance, measured at $532 \mathrm{~nm}$ ), as shown in Figure 5B for bulk $\mathrm{MoS}_{2}$. Also, sensitivity of the capacitance to illumination is potential-dependent with the largest changes being most pronounced at high potentials, that is, low electron energies (Supporting Figure S13). This is consistent with the ntype doping of natural $\mathrm{MoS}_{2}$; it behaves as a dark cathode/ photoanode and the photoconductive behavior is therefore most prominent at high potentials. ${ }^{16,17,19}$ The EDLC also depends on the number of $\mathrm{MoS}_{2}$ layers, as shown in Figure 5C, which is especially noticeable for the low conductivity sample G. Furthermore, a linear correlation exists between the decimal logarithm of $k^{0}$ and EDLC with both values determined on the same surface (Figure 5D). This holds for two samples of differing intrinsic conductivity determined qualitatively from the ET measurement $\left(\mathrm{C}\right.$, high conductivity, bulk $k^{0} \sim 1.43 \times$ $10^{-3} \mathrm{~cm} \mathrm{~s}^{-1}$ at $0.04 \mathrm{~W} \mathrm{~cm}^{-2}$; and $\mathrm{G}$, low conductivity, bulk $k^{0} \sim$ $0.81 \times 10^{-3} \mathrm{~cm} \mathrm{~s}^{-1}$ at $0.67 \mathrm{~W} \mathrm{~cm}^{-2}$ ). Interestingly, although a relationship between the ET kinetics and EDLC was previously reported for glassy carbon and highly ordered pyrolytic graphite, ${ }^{47,48}$ there is a clear lack of description of an explicit quantitative correlation between these two properties and its fundamental explanation for semimetallic and semiconducting electrodes. $^{49}$

The ET kinetics was also plotted against the maximum intensity and corresponding wavelength of $\mathrm{MoS}_{2}$ photoluminescence. While the kinetics on bulk $\mathrm{MoS}_{2}$ (Figure 5E) do not correlate well with the PL wavelength (red triangles), there is a weak underlying trend with the PL intensity (blue crosses). The kinetics of a monolayer $\mathrm{MoS}_{2}$ (Figure 5F) show a general increasing trend with increasing PL wavelength and intensity, despite the scattered data.

Photocurrent as a Function of $\mathrm{MoS}_{2}$ Thickness. Further assessment of $\mathrm{MoS}_{2}$ performance as an electrode can be gleaned from voltammetric measurements in pure electrolyte $(6$ $\mathrm{M} \mathrm{LiCl}$ ), which are shown in Figure 6. The illumination clearly affects the voltammetry of both $\mathrm{MoS}_{2}$ samples despite their differing conductivity ( $\mathrm{C}$, high and $\mathrm{G}$, low), and significant differences are observed between the monolayer, few-layer, and bulk $\mathrm{MoS}_{2}$. Let us first discuss the higher conductivity sample 

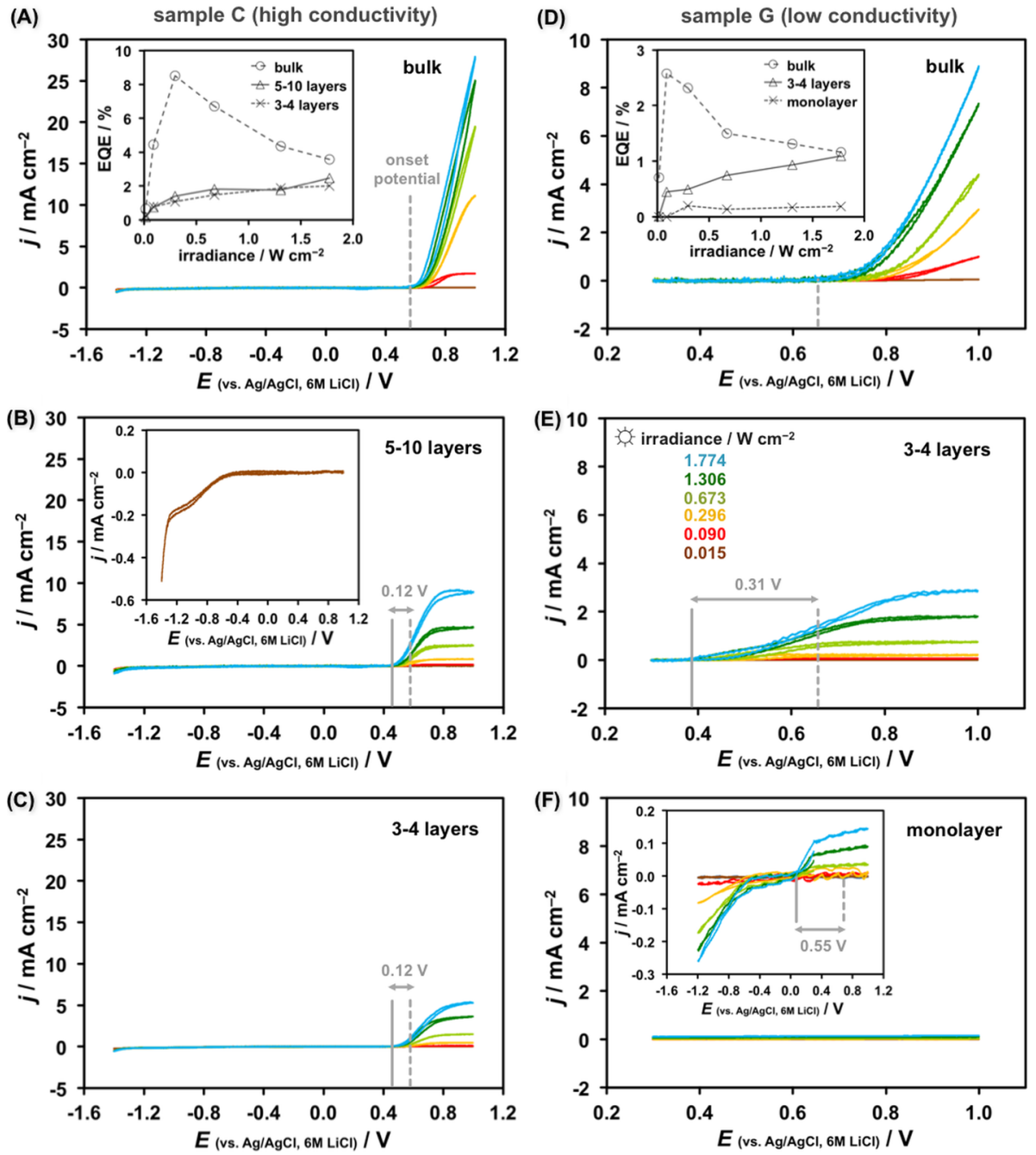

Figure 6. Photoanodic behavior of $\mathrm{MoS}_{2}$ and its dependence on the number of layers. (A-C) Series of cyclic voltammograms recorded for bulk, 510 layers, and 3-4 layers of a high conductivity $\mathrm{MoS}_{2}$ sample, respectively. (D-F) Positive potential branches of voltammograms recorded on bulk, 3-4 layers, and a monolayer of a low conductivity $\mathrm{MoS}_{2}$ sample, respectively. The insets in (A,D) show the dependence of the EQE, calculated from eq 5 , on the irradiance. The different colors of the voltammetric curves correspond to the different irradiance values shown in (E). Zooms of the lowest-irradiance voltammogram and the low-current monolayer response are shown in the insets of (B,F), respectively.

(Figure 6A-C). A large photocurrent, most likely originating from water oxidation, chloride oxidation and/or sulfate formation, ${ }^{16,50,51}$ is observed above $0.6 \mathrm{~V}$ for the bulk $\mathrm{MoS}_{2}$ as shown in Figure 6A. For the irradiance up to ca. $0.3 \mathrm{~W} \mathrm{~cm}^{-2}$, the photocurrent reaches a plateau, whose height increases with illumination. Above this irradiance, the current increases monotonously with potential. For $\mathrm{MoS}_{2}$ about 5-10 layers thick, the photocurrent reaches a plateau even for the highest irradiance $\left(1.8 \mathrm{~W} \mathrm{~cm}^{-2}\right)$ and has ca. $3 \times$ lower magnitude than the bulk (Figure 6B). Further decrease in the photocurrent is observed for $\mathrm{MoS}_{2}$ 3-4 layers thick (Figure 6C). The photocurrent in the lower conductivity sample $G$, which is on average $2-3 \times$ lower than that of sample $C$, exhibits slightly different behavior. The bulk $\mathrm{MoS}_{2}$ photocurrent does not reach a plateau for any of the illumination intensities used. Instead, the photocurrent increases exponentially with the potential, increasing in magnitude with the irradiance (Figure 6D). The photocurrent of 3-4 layer thick $\mathrm{MoS}_{2}$ reaches a plateau (Figure $6 \mathrm{E})$ and only small photocurrent response is observed for the monolayer $\mathrm{MoS}_{2}$ due to its poor conductivity (Figure 6F). Importantly, for both samples there is a consistent shift in the photocurrent onset potential between the bulk and thin $\mathrm{MoS}_{2}$ flakes. In the case of sample $\mathrm{C}$, the onset potential is decreased by $\sim 0.12 \mathrm{~V}$ for thin flakes (3-4 and 5-10 layers) in comparison to bulk $\mathrm{MoS}_{2}$.

This is much more pronounced for sample G with $\sim 0.31 \mathrm{~V}$ onset potential downshift for 3-4 layers in comparison to bulk $\mathrm{MoS}_{2}$, and an overall downshift of $\sim 0.55 \mathrm{~V}$ between monolayer and bulk $\mathrm{MoS}_{2}$. The shift in the onset potential can be interpreted as a direct representation of the difference between the work functions of monolayer and bulk $\mathrm{MoS}_{2}$ (5.1 and 4.5 $\mathrm{eV}$, respectively). ${ }^{52}$ As illustrated with a simplified band diagram in Figure 7, the work functions of monolayer and bulk $\mathrm{MoS}_{2}$ define their Fermi levels $\left(E_{\mathrm{F}}\right){ }^{28}$ The photoanodic oxidation reaction discussed here is represented by a DOS distribution function $D_{\mathrm{R}}(E)$ at the energy level corresponding to the reduced form of a species $\mathrm{R}$ at $\mathrm{MoS}_{2}$ /liquid interface. In order to oxidize $\mathrm{R}$, the energy level of the electron receiving states in $\mathrm{MoS}_{2}$ must be equal or lower than the energy level of the occupied states of $\mathrm{R}^{28}$ Figure 7 shows that while the Fermi levels of both monolayer and bulk $\mathrm{MoS}_{2}$ have to be lowered for the oxidation to proceed, $E_{\mathrm{F}}{ }^{\text {mono }}$ requires a smaller shift in 


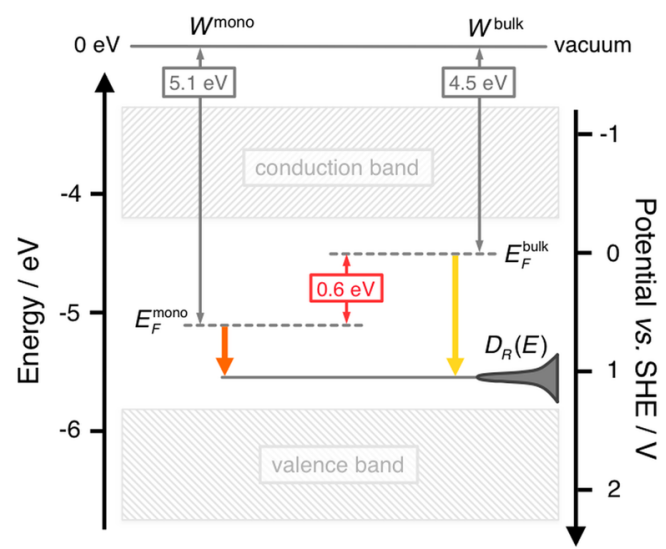

Figure 7. A simplified band diagram illustrating the effect of differing work functions of monolayer and bulk $\mathrm{MoS}_{2}$ on the oxidation onset potential. The energy levels are approximate and the potential scale is referenced versus the standard hydrogen electrode (SHE).

energy (potential) than $E_{\mathrm{F}}^{\text {bulk }}$. Therefore, an oxidation reaction at $\mathrm{MoS}_{2}$ surface will proceed more easily on a monolayer than bulk. The onset potential difference of $\sim 0.55 \mathrm{~V}$ between monolayer and bulk $\mathrm{MoS}_{2}$ closely matches the $0.6 \mathrm{eV}$ difference between their work functions. (We should add that the while the exact Fermi level position will be affected by the junction potential at the solid/liquid, the relative difference between $E_{F}$ mono and $E_{F}^{\text {bulk }}$ arising from the differing work functions should be maintained.) The difference in work functions explains the potential shift well, although we cannot rule out other causes, such as doping effects from the PMMA substrate, which have been shown to affect mobility of $\mathrm{MoS}_{2}$ over a surprisingly long vertical distances. ${ }^{41}$

Importantly, no significant photocorrosion of mono- and few-layer $\mathrm{MoS}_{2}$ under high illumination, current, or repeated voltammetric cycling was observed and therefore majority of the photoanodic current in Figure 6 originates from water or chloride oxidation rather than oxidation of the $\mathrm{MoS}_{2}$ surface. The photocorrosion resistance can be attributed to a stable anodic oxidation mechanism, which is supported by formation of holes in the d-orbitals of Mo, as previously noted for bulk $\mathrm{MoS}_{2} \cdot{ }^{50}$ We have also calculated the external quantum efficiencies (EQE) of the incident photon-to-photocurrent conversion, which are shown in the inset of Figure $6 \mathrm{~A}, \mathrm{D}$ as a function of irradiance. The EQE was calculated as

$$
\operatorname{EQE}(\%)=100 \times \frac{N_{\mathrm{e}}}{\left(1-T_{\mathrm{r}}\right) N_{\mathrm{h} \nu}}=100 \times \frac{I_{\mathrm{p}}}{e} \frac{\varepsilon}{\left(1-T_{\mathrm{r}}\right) E_{\mathrm{e}}}
$$

where $N_{\mathrm{e}}$ is the number of electrons generated per second, $N_{\mathrm{h} \nu}$ is the number of incident photons per second, $I_{\mathrm{p}}$ is the generated photocurrent, $e=1.60217657 \times 10^{-19} \mathrm{P}$ is the elementary charge, $E_{\mathrm{e}}$ is the irradiance, and $\varepsilon$ is the energy of a single photon quantum, calculated as $\varepsilon=h c / \lambda$, where $h=6.626$ $\times 10^{-34} \mathrm{~J} \mathrm{~s}$ is the Planck constant, $c=2.998 \times 10^{8} \mathrm{~m} \mathrm{~s}^{-1}$ is the speed of light in air, and $\lambda=532 \mathrm{~nm}$ is an arbitrary photon wavelength. $T_{\mathrm{r}}$ is the transmittance, calculated as

$$
T_{\mathrm{r}}=(1-x)^{n}
$$

where $x$ is the fraction of light absorbed by one layer $(x \approx 0.1)$ and $n$ is the number of $\mathrm{MoS}_{2}$ layers.

The maximum EQE reaches $8.5 \%$ for bulk $\mathrm{MoS}_{2}$ (sample C), which significantly exceeds previously reported values. $16,50,53$
Interestingly, while the EQE of thin $\mathrm{MoS}_{2}$ ( $<10$ layers) decreases monotonously with decreasing irradiance, the EQE of bulk $\mathrm{MoS}_{2}$ show a maximum between $0.1-0.3 \mathrm{~W} \mathrm{~cm}^{-2}$, which is close to the solar constant value (see Supporting Figure 2).

This study highlights the critical influence of the number of layers and illumination on electrochemical properties of $\mathrm{MoS}_{2}$, which in turn affect performance of this material in energy storage/conversion, sensing, and electrocatalysis. We have successfully measured the electron transfer kinetics and capacitance of pristine mono- and few-layer basal plane $\mathrm{MoS}_{2}$ and found that they both increase with the growing number of $\mathrm{MoS}_{2}$ layers and increasing irradiance. Our interpretation of these results is based on a multilayer absorption of photons in bulk $\mathrm{MoS}_{2}$ and subsequent interlayer transport of photogenerated charge carriers, which contributes to the enlarged photoelectrochemical response of bulk $\mathrm{MoS}_{2}$ in comparison to monolayer $\mathrm{MoS}_{2}$. The detailed analysis reveals that while the ET kinetics depends linearly on irradiance for bulk $\mathrm{MoS}_{2}$, a nonlinear behavior is observed for monolayer $\mathrm{MoS}_{2}$. This is explained by differing diffusion mechanism of charge carriers within monolayer and bulk $\mathrm{MoS}_{2}$. It should be noted that although the relative changes in the ET kinetics reflect differences in the electrochemical activity of $\mathrm{MoS}_{2}$, the ET kinetics absolute value is determined by the self-exchange rate of the $\left[\mathrm{Ru}\left(\mathrm{NH}_{3}\right)_{6}\right]^{3+/ 2+}$ redox mediator used as an ET probe. Importantly, we have observed consistent shifts between the anodic photocurrent onset potentials of thick and thin $\mathrm{MoS}_{2}$ layers, which are explained by a difference in the work functions of bulk and monolayer $\mathrm{MoS}_{2}$. The excellent photocorrosion stability and sensitivity of mono- and few-layer basal plane $\mathrm{MoS}_{2}$ to extrinsic impurities, substrate identity, and illumination can be exploited in sensing and as a control of industrially important reactions, such as water oxidation, halide oxidation, and hydrogen evolution.

Methods. Materials and Chemicals. Hexaammineruthenium(III) chloride (98\%), lithium chloride (99\%), and potassium chloride (99\%) were purchased from Sigma-Aldrich, U.K. and used as received. Aqueous solutions were prepared using deionized water $(18.2 \mathrm{M} \Omega \mathrm{cm}$, Milli-Q Direct 8, Merck Millipore, U.S.A.). $\mathrm{Cu}, \mathrm{Ag}$, and $\mathrm{Pt}$ wires (>99.9\%) were purchased from Advent Research Materials, U.K., and silver conductive paint was obtained from RS Components Ltd., U.K. The $\mathrm{Ag} / \mathrm{AgCl}$ reference electrode was prepared by oxidation of a $\mathrm{Ag}$ wire in $0.1 \mathrm{M} \mathrm{KCl} . \mathrm{MoS}_{2}$ flakes were prepared by mechanical exfoliation of natural molybdenite crystals (Manchester Nanomaterials Ltd., U.K.) onto Si wafers (IBD Technologies, U.K.) spin-coated with $\sim 100 \mathrm{~nm}$ layer of PMMA (MicroChem Corp, MA, U.S.A.).

$\mathrm{MoS}_{2}$ Characterization. A Nikon Eclipse LV100ND optical microscope and a DS-Fi2 U3 CCD camera (Nikon Metrology, U.K. Ltd.) were used to visualize $\mathrm{MoS}_{2}$ flakes and liquid droplets using bright-field and dark-field illumination modes. The microscope illumination power density (irradiance) was calibrated using the $843-\mathrm{R}$ power meter with a NIST-calibrated 818-Sl Si photodiode (Newport Spectra-Physics Ltd., U.K.). Complementary Raman spectroscopy and PL measurement were used to assess the quality of the surface and obtained using an inVia spectrometer with unpolarized $532 \mathrm{~nm}$ laser excitation ( $<5 \mathrm{~mW}), 1800$ grooves/mm grating and a $100 \times$ Leica objective (Renishaw plc, U.K.). AFM measurements were performed with a Bruker Dimension $3100 \mathrm{~V}$ instrument in tapping mode with the tip resonance frequency of $\sim 350 \mathrm{kHz}$ (see Supporting Figure S1 for example analysis). XPS spectra 
acquisition and imaging was performed on an AXIS Nova instrument (Kratos Analytical Ltd., U.K.) and analyzed using CasaXPS software v.2.3 (Casa Software Ltd.).

Experimental Setup. $\mathrm{MoS}_{2}$ flakes were electrically connected to a copper wire using a silver conductive paint and employed as working electrodes (WE) as shown in Figure 1C. Aqueous droplets of either $6 \mathrm{M} \mathrm{LiCl}$ electrolyte or redox mediator solution $\left(3 \mathrm{mM} \mathrm{Ru}\left(\mathrm{NH}_{3}\right)_{6} \mathrm{Cl}_{3}\right.$ in $\left.6 \mathrm{M} \mathrm{LiCl}\right)$ were formed using a borosilicate micropipette (ca. $1 \mu \mathrm{m}$ internal tip diameter) and a pneumatic microinjector (PV820 Pneumatic PicoPump, WPI, U.S.A.). The high concentration of aqueous electrolyte (6 M $\mathrm{LiCl}$ ) was necessary to prevent unwanted microdroplet evaporation and was validated in our previous work. ${ }^{19,24,25,27,54}$ Vertical and horizontal motion of the micropipette with embedded $\mathrm{Ag} / \mathrm{AgCl}$ reference electrode (RE) and Pt counter electrode (CE) was controlled using a MX7630 micromanipulator and a MC 1000e motion controller (Siskiyou, Oregon, U.S.A.). In this three-electrode configuration, the electron transfer and capacitance at the $\mathrm{MoS}_{2}$ / droplet interface were measured using potentiostats PGSTAT302N (Metrohm Autolab B.V., The Netherlands) and CompactStat.e (Ivium Technologies, The Netherlands), respectively, with the potential measured against an $\mathrm{Ag} / \mathrm{AgCl}$ reference electrode in $6 \mathrm{M} \mathrm{LiCl}$, which is ca. $+0.19 \mathrm{~V}$ on the SHE scale. All measurements were performed at ambient temperature $\left(21-25^{\circ} \mathrm{C}\right)$.

\section{ASSOCIATED CONTENT}

\section{S Supporting Information}

The Supporting Information is available free of charge on the ACS Publications website at DOI: 10.1021/acs.nanolett.5b05317.

Further $\mathrm{MoS}_{2}$ characterization, illumination power density calibration, Raman and Pl spectra versus $\mathrm{MoS}_{2}$ thickness calibration, high-resolution XPS spectra and XPS imaging of $\mathrm{MoS}_{2}$, heterogeneity of Raman and PL spectra in monolayer $\mathrm{MoS}_{2}$, dependence of electron transfer/capacitance on electrode area, intralayer resistance effects on ET kinetics, ET kinetics of individual $\mathrm{MoS}_{2}$ samples, and dependence of capacitance on scan rate and illumination. (PDF)

\section{AUTHOR INFORMATION}

\section{Corresponding Authors}

*E-mail: matej.velicky@manchester.ac.uk. Tel: +44 (0)161306-4522. Fax: +44 (0)161-275-4598.

*E-mail: robert.dryfe@manchester.ac.uk. Tel: +44 (0)161-3064522. Fax: +44 (0)161-275-4598.

\section{Notes}

The authors declare no competing financial interest.

\section{ACKNOWLEDGMENTS}

The authors thank EPSRC (Grants EP/I005145/1 and EP/ K016954/1) and BGT Materials Ltd. for funding, Dr. Jose Portoles at nanoLAB (Newcastle University) for XPS spectra and imaging measurements, Dr. Freddie Withers (Manchester University) for advice with sample preparation, and Dr. Andrew Rodgers and Dr. Hollie Patten (both Manchester University) for useful discussions.

\section{REFERENCES}

(1) Chhowalla, M.; Shin, H. S.; Eda, G.; Li, L. J.; Loh, K. P.; Zhang, H. Nat. Chem. 2013, 5 (4), 263-275.

(2) Salomon, G.; De Gee, A. W. J.; Zaat, J. H. Wear 1964, 7 (1), 87101.

(3) Wang, Q. H.; Kalantar-Zadeh, K.; Kis, A.; Coleman, J. N.; Strano, M. S. Nat. Nanotechnol. 2012, 7 (11), 699-712.

(4) Cui, X.; Lee, G.-H.; Kim, Y. D.; Arefe, G.; Huang, P. Y.; Lee, C.H.; Chenet, D. A.; Zhang, X.; Wang, L.; Ye, F.; Pizzocchero, F.; Jessen, B. S.; Watanabe, K.; Taniguchi, T.; Muller, D. A.; Low, T.; Kim, P.; Hone, J. Nat. Nanotechnol. 2015, 10 (6), 534-540.

(5) Ye, J. T.; Zhang, Y. J.; Akashi, R.; Bahramy, M. S.; Arita, R.; Iwasa, Y. Science 2012, 338 (6111), 1193-1196.

(6) Kasowski, R. V. Phys. Rev. Lett. 1973, 30 (23), 1175-1178.

(7) Splendiani, A.; Sun, L.; Zhang, Y.; Li, T.; Kim, J.; Chim, C.-Y.; Galli, G.; Wang, F. Nano Lett. 2010, 10 (4), 1271-1275.

(8) Novoselov, K. S.; Jiang, D.; Schedin, F.; Booth, T. J.; Khotkevich, V. V.; Morozov, S. V.; Geim, A. K. Proc. Natl. Acad. Sci. U. S. A. 2005, 102 (30), 10451-10453.

(9) Coleman, J. N.; Lotya, M.; O’Neill, A.; Bergin, S. D.; King, P. J.; Khan, U.; Young, K.; Gaucher, A.; De, S.; Smith, R. J.; Shvets, I. V.; Arora, S. K.; Stanton, G.; Kim, H. Y.; Lee, K.; Kim, G. T.; Duesberg, G. S.; Hallam, T.; Boland, J. J.; Wang, J. J.; Donegan, J. F.; Grunlan, J. C.; Moriarty, G.; Shmeliov, A.; Nicholls, R. J.; Perkins, J. M.; Grieveson, E. M.; Theuwissen, K.; McComb, D. W.; Nellist, P. D.; Nicolosi, V. Science 2011, 331 (6017), 568-571.

(10) Jeon, J.; Jang, S. K.; Jeon, S. M.; Yoo, G.; Jang, Y. H.; Park, J.-H.; Lee, S. Nanoscale 2015, 7 (5), 1688-1695.

(11) Al-Mamun, M.; Zhang, H.; Liu, P.; Wang, Y.; Cao, J.; Zhao, H. RSC Adv. 2014, 4 (41), 21277-21283.

(12) Chang, K.; Chen, W. ACS Nano 2011, 5 (6), 4720-4728.

(13) Lei, B.; Li, G. R.; Gao, X. P. J. Mater. Chem. A 2014, 2 (11), 3919-3925.

(14) Bissett, M. A.; Kinloch, I. A.; Dryfe, R. A. W. ACS Appl. Mater. Interfaces 2015, 7 (31), 17388-17398.

(15) Voiry, D.; Salehi, M.; Silva, R.; Fujita, T.; Chen, M.; Asefa, T.; Shenoy, V. B.; Eda, G.; Chhowalla, M. Nano Lett. 2013, 13 (12), $6222-6227$

(16) Tributsch, H.; Bennett, J. C. J. Electroanal. Chem. Interfacial Electrochem. 1977, 81 (1), 97-111.

(17) Ahmed, S. M. Electrochim. Acta 1982, 27 (6), 707-712.

(18) Tan, S. M.; Ambrosi, A.; Sofer, Z.; Huber, Š.; Sedmidubský, D.; Pumera, M. Chem. - Eur. J. 2015, 21 (19), 7170-7178.

(19) Velický, M.; Bissett, M. A.; Toth, P. S.; Patten, H. V.; Worrall, S. D.; Rodgers, A. N. J.; Hill, E. W.; Kinloch, I. A.; Novoselov, K. S.; Georgiou, T.; Britnell, L.; Dryfe, R. A. W. Phys. Chem. Chem. Phys. 2015, 17 (27), 17844-17853.

(20) Wang, Y.; Ou, J. Z.; Balendhran, S.; Chrimes, A. F.; Mortazavi, M.; Yao, D. D.; Field, M. R.; Latham, K.; Bansal, V.; Friend, J. R.; Zhuiykov, S.; Medhekar, N. V.; Strano, M. S.; Kalantar-Zadeh, K. ACS Nano 2013, 7 (11), 10083-10093.

(21) Chia, X.; Ambrosi, A.; Sedmidubský, D.; Sofer, Z.; Pumera, M. Chem. - Eur. J. 2014, 20 (52), 17426-17432.

(22) Yu, Y.; Huang, S.-Y.; Li, Y.; Steinmann, S. N.; Yang, W.; Cao, L. Nano Lett. 2014, 14 (2), 553-558.

(23) Li, W.; Tan, C.; Lowe, M. A.; Abruña, H. D.; Ralph, D. C. ACS Nano 2011, 5 (3), 2264-2270.

(24) Velický, M.; Bradley, D. F.; Cooper, A. J.; Hill, E. W.; Kinloch, I. A.; Mishchenko, A.; Novoselov, K. S.; Patten, H. V.; Toth, P. S.; Valota, A. T.; Worrall, S. D.; Dryfe, R. A. W. ACS Nano 2014, 8 (10), 10089-10100.

(25) Velický, M.; Cooper, A. J.; Toth, P. S.; Patten, H. V.; Woods, C. R; Novoselov, K. S.; Dryfe, R. A. W. 2 D Mater. 2015, 2 (2), 024011.

(26) Güell, A. G.; Cuharuc, A. S.; Kim, Y.-R.; Zhang, G.; Tan, S.-y.; Ebejer, N.; Unwin, P. R. ACS Nano 2015, 9 (4), 3558-3571.

(27) Toth, P. S.; Valota, A.; Velický, M.; Kinloch, I.; Novoselov, K.; Hill, E. W.; Dryfe, R. A. W. Chem. Sci. 2014, 5 (2), 582-589. 
(28) Bard, A. J.; Faulkner, L. R. Electrochemical Methods. Fundamentals and Applications, 2nd ed.; John Wiley \& Sons, Inc.: New York, 2001.

(29) Dolui, K.; Rungger, I.; Sanvito, S. Phys. Rev. B: Condens. Matter Mater. Phys. 2013, 87 (16), 165402.

(30) Li, H.; Zhang, Q.; Yap, C. C. R.; Tay, B. K.; Edwin, T. H. T.; Olivier, A.; Baillargeat, D. Adv. Funct. Mater. 2012, 22 (7), 1385-1390.

(31) Frindt, R. F. J. Appl. Phys. 1966, 37 (4), 1928-1929.

(32) Lee, C.; Yan, H.; Brus, L. E.; Heinz, T. F.; Hone, J.; Ryu, S. ACS Nano 2010, 4 (5), 2695-2700.

(33) Klingler, R. J.; Kochi, J. K. J. Phys. Chem. 1981, 85 (12), 17311741.

(34) Nicholson, R. S. Anal. Chem. 1965, 37 (11), 1351-1355.

(35) Lavagnini, I.; Antiochia, R.; Magno, F. Electroanalysis 2004, 16 (6), 505-506.

(36) Dolui, K.; Rungger, I.; Das Pemmaraju, C.; Sanvito, S. Phys. Rev. B: Condens. Matter Mater. Phys. 2013, 88 (7), 075420.

(37) Zhou, W.; Zou, X.; Najmaei, S.; Liu, Z.; Shi, Y.; Kong, J.; Lou, J.; Ajayan, P. M.; Yakobson, B. I.; Idrobo, J.-C. Nano Lett. 2013, 13 (6), $2615-2622$.

(38) Baugher, B. W. H.; Churchill, H. O. H.; Yang, Y.; JarilloHerrero, P. Nano Lett. 2013, 13 (9), 4212-4216.

(39) Late, D. J.; Liu, B.; Matte, H. S. S. R.; Dravid, V. P.; Rao, C. N. R. ACS Nano 2012, 6 (6), 5635-5641.

(40) McDonnell, S.; Addou, R.; Buie, C.; Wallace, R. M.; Hinkle, C. L. ACS Nano 2014, 8 (3), 2880-2888.

(41) Bao, W.; Cai, X.; Kim, D.; Sridhara, K.; Fuhrer, M. S. Appl. Phys. Lett. 2013, 102 (4), 042104.

(42) Tonndorf, P.; Schmidt, R.; Böttger, P.; Zhang, X.; Börner, J.; Liebig, A.; Albrecht, M.; Kloc, C.; Gordan, O.; Zahn, D. R. T.; De Vasconcellos, S. M.; Bratschitsch, R. Opt. Express 2013, 21 (4), 49084916.

(43) Bernardi, M.; Palummo, M.; Grossman, J. C. Nano Lett. 2013, 13 (8), 3664-3670.

(44) Liu, J.-T.; Wang, T.-B.; Li, X.-J.; Liu, N.-H. J. Appl. Phys. 2014, 115 (19), 193511.

(45) Son, Y.; Wang, Q. H.; Paulson, J. A.; Shih, C.-J.; Rajan, A. G.; Tvrdy, K.; Kim, S.; Alfeeli, B.; Braatz, R. D.; Strano, M. S. ACS Nano 2015, 9 (3), 2843-2855.

(46) Xiong, G.; Meng, C.; Reifenberger, R. G.; Irazoqui, P. P.; Fisher,

T. S. Electroanalysis 2014, 26 (1), 30-51.

(47) Rice, R. J.; Pontikos, N. M.; McCreery, R. I. J. Am. Chem. Soc. 1990, 112 (12), 4617-4622.

(48) Rice, R. J.; McCreery, R. L. Anal. Chem. 1989, 61 (15), 16371641.

(49) Liu, Y.; Chen, S. J. Electroanal. Chem. 2015, 753, 3-8.

(50) Tributsch, H. Faraday Discuss. Chem. Soc. 1980, 70, 189-205.

(51) Kubiak, C. P.; Schneemeyer, L. F.; Wrighton, M. S. J. Am. Chem. Soc. 1980, 102 (22), 6898-6900.

(52) Britnell, L.; Ribeiro, R. M.; Eckmann, A.; Jalil, R.; Belle, B. D.; Mishchenko, A.; Kim, Y.-J.; Gorbachev, R. V.; Georgiou, T.; Morozov, S. V.; Grigorenko, A. N.; Geim, A. K.; Casiraghi, C.; Neto, A. H. C.; Novoselov, K. S. Science 2013, 340 (6138), 1311-1314.

(53) Kline, G.; Kam, K. K.; Ziegler, R; Parkinson, B. A. Sol. Energy Mater. 1982, 6 (3), 337-350.

(54) Valota, A. T.; Toth, P. S.; Kim, Y. J.; Hong, B. H.; Kinloch, I. A.; Novoselov, K. S.; Hill, E. W.; Dryfe, R. A. W. Electrochim. Acta 2013, $110,9-15$. 